\title{
Ectopic micronodular thymoma with lymphoid stroma in the cervical region: a rare case associated with Langerhans cells proliferation
}

This article was published in the following Dove Press journal:

OncoTargets and Therapy

18 July 2016

Number of times this article has been viewed

Min Yu'

Yuan Meng²

Bin $X u^{2}$

Lin Zhao ${ }^{3}$

Qingfu Zhang ${ }^{4}$

'Department of Cell Biology, Key Laboratory of Cell Biology, Ministry of Public Health, and Key Laboratory of Medical Cell Biology, Ministry of Education, China Medical University, Shenyang, People's Republic of China; ${ }^{2}$ Department of Pathology, Fushun Central Hospital, Fushun, People's Republic of China; ${ }^{3}$ Second Department of Medical Oncology, The General Hospital of Fushun Mining Bureau, Fushun, People's Republic of China; ${ }^{4}$ Department of Pathology, College of Basic Medical Sciences, China Medical University, Shenyang, People's Republic of China
Correspondence: Qingfu Zhang Department of Pathology, College of Basic Medical Sciences, China Medical University, No 77 Puhe Road, Shenyang North New Area, Shenyang I I0I22, Liaoning Province, People's Republic of China

Email qfzhang@cmu.edu.cn
Abstract: Micronodular thymoma (MNT) with lymphoid stroma is a rare thymic epithelial neoplasm with the characteristics of multiple nodules separated by abundant lymphoid stroma. MNTs mainly arise in the anterior mediastinum and thymus, while ectopic MNTs are extremely rarely seen. Here, we report an ectopic MNT that occurred in the neck of a 62-year-old woman. There were also scattered eosinophilic granulocytes and $\mathrm{S} 100^{+} / \mathrm{CD} 1 \mathrm{a}^{+}$Langerhans cells within the tumor. This case provides a better understanding of such rare, poorly understood cases.

Keywords: ectopic, micronodular thymoma, lymphoid stroma, Langerhans cell

\section{Introduction}

Thymomas are derived from thymic epithelial cells. ${ }^{1}$ There are several types of thymomas based on the morphology of tumor cells and distribution of $\mathrm{T}$ lymphocytes, among which micronodular thymomas (MNTs) are rare and account for less than 5\% of all thymomas. ${ }^{2}$

As first described by Suster and Moran in $1999,{ }^{3}$ MNTs mainly occur in elderly people and have the characteristics of numerous tumor nodules and abundant lymphoid stroma. The majority of MNTs arise in the anterior mediastinum and thymus, while only three have been reported to be ectopically located in the neck. ${ }^{46} \mathrm{Here}$, we report an additional ectopic MNT (eMNT) located behind the right ear in the neck of a 62-year-old woman.

\section{Case presentation}

A 62-year-old woman was admitted to our hospital because of a growing cervical mass. Computed tomography (CT) demonstrated a high-density spot shadow, $6 \mathrm{~mm}$ in diameter, in her right thyroid. The mass was removed via extended resection and diagnosed as a thyroid papillary microcarcinoma. Medical informed consent and written informed consent to particpate in this case report were obtained from the patient.

Six months after surgery, some other masses were noted behind the right ear in her neck. The patient had no symptoms of fever, myasthenia gravis, or other autoimmune diseases. Cervical CT revealed several nodulated masses, of which the largest one was nearly $28 \times 24 \mathrm{~mm}$ (Figure 1 ). The adjacent blood vessels and submandibular gland were constricted by the masses. The masses were suspected to be metastatic cancer and were removed during biopsy.

Hematoxylin and eosin staining showed that the masses were an eMNT. Histologically, it was composed of multiple tumor nodules separated by hyperplastic lymphoid tissues with prominent germinal centers (Figure 2A). The tumor cells within the 


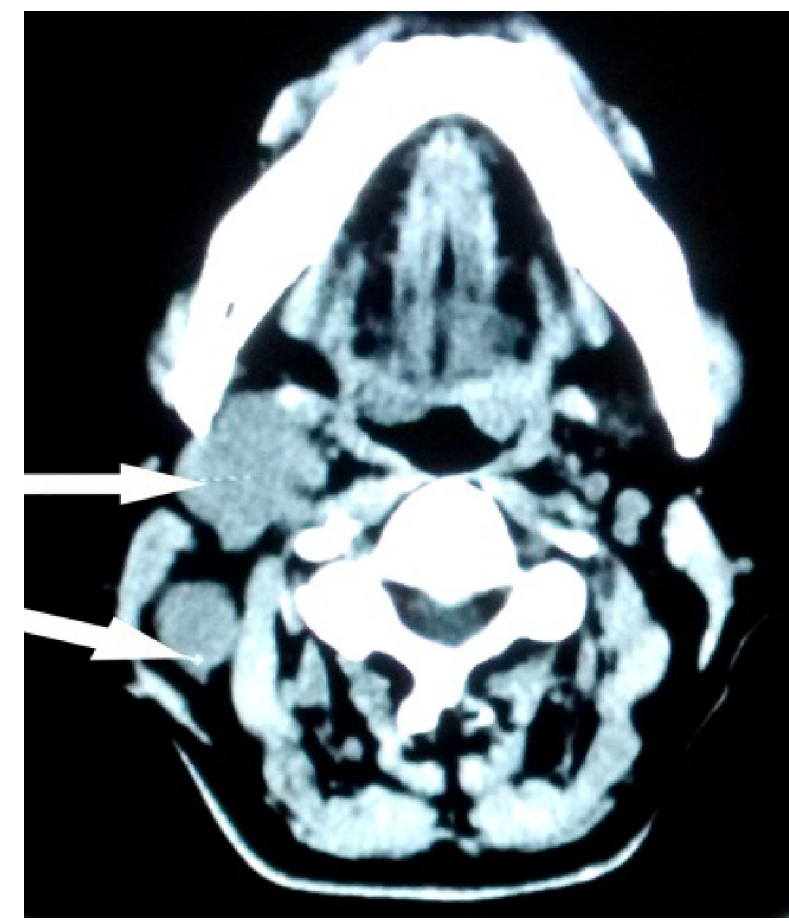

Figure I Cervical CT image.

Note: Cervical CT showed several inhomogeneous nodules (indicated by the arrows) near the cervical vessels.

Abbreviation: CT, computed tomography. nodules were mostly oval-to-spindle shaped, with nuclei containing dispersed chromatin and inconspicuous nucleoli (Figure 2B). Atypia and mitotic activity were occasionally observed. Eosinophilic granulocytes were found to infiltrate the tumor nodules and the surrounding lymphoid stroma (Figure 2C). Langerhans cells (LCs) were mainly scattered within the tumor nodules, and nuclear grooves could be observed (Figure 2D). The lymphoid stroma was composed of mature lymphocytes with formation of lymphoid follicles with prominent germinal centers. Mature plasma cells were occasionally observed, while thymic corpuscles and perivascular spaces were absent.

The following antibodies (Table 1) were used for immunohistochemical staining. The tumor cells in the nodules showed strong positivity for pan-CK (Figure 3A), CK5/6 (Figure 3B), and P63 (Figure 3C), while they were negative for CD20, CK20, and CK7. The Ki67 proliferation index was about $10 \%$. CD1a (Figure 3D) and S100 (Figure 3E) staining showed that the proliferating LCs were distributed in the tumor nodules. The hyperplastic stroma was primarily formed by large numbers of mature $B$ lymphocytes expressing Pax-5 (Figure $3 \mathrm{~F}$ ) and CD20 as well as mature T lymphocytes
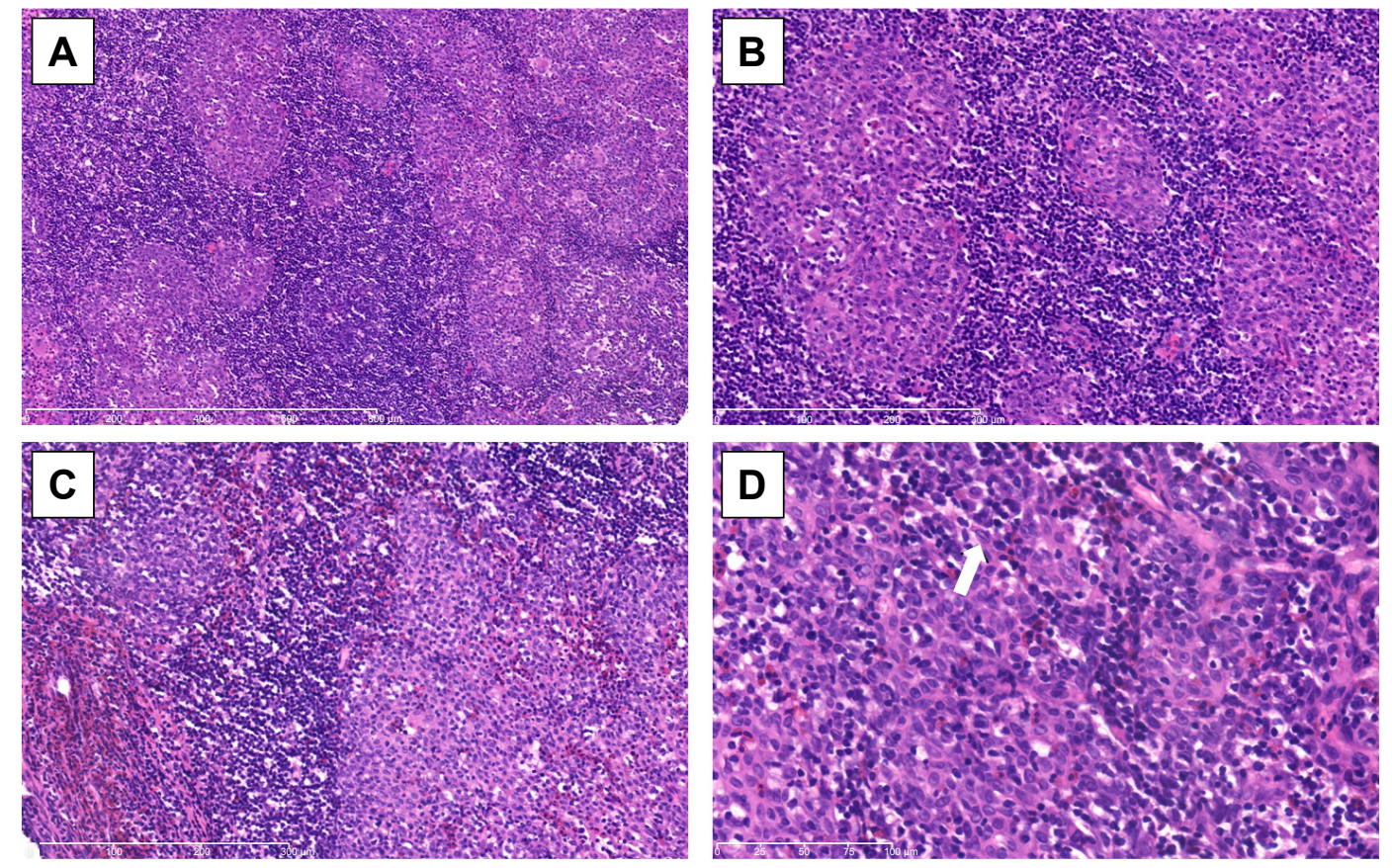

Figure 2 Hematoxylin and eosin staining of the thymoma.

Notes: (A) Tumor cells were arranged in a nodular pattern. The infiltrated stroma contained large numbers of lymphocytes with formation of lymphoid follicles. Scale bar is $800 \mu \mathrm{m}$. (Original magnification $\times 100$.) (B) Epithelial tumor cells were oval shaped with occasionally atypia or mitotic activity. Scale bar is $300 \mu \mathrm{m}$. (Original magnification $\times 200$.) $(\mathbf{C})$ Eosinophilic granulocytes infiltrated the tumor nodules and the surrounding stroma. Scale bar is $300 \mu \mathrm{m}$. (Original magnification $\times 200$.) $(\mathbf{D}) \mathrm{High}$ magnification showed the infiltrated eosinophilic granulocytes and the proliferating LCs. Nuclear grooves (indicated by the arrow) could be observed in some LCs. Scale bar is $100 \mu \mathrm{m}$. (Original magnification $\times 100$.)

Abbreviation: LCs, Langerhans cells. 
Table I Immunohistochemical staining reagents of the eMNT

\begin{tabular}{lllll}
\hline Antibody & Clone & Source & Dilution & Results \\
\hline CK (pan) & AEI/AE3 & Fuzhou Maixin Biology, Fuzhou, People's Republic of China & Ready to use & + \\
CK5/6 & D5/I6B4 & Fuzhou Maixin Biology, Fuzhou, People's Republic of China & Ready to use & + \\
CK7 & OV-TL I2/30 & Fuzhou Maixin Biology, Fuzhou, People's Republic of China & Ready to use & - \\
CK20 & Ks20.8 & Fuzhou Maixin Biology, Fuzhou, People's Republic of China & Ready to use & Tumor cells-, lymphocyte+ \\
CDIa & OI0 & Fuzhou Maixin Biology, Fuzhou, People's Republic of China & Ready to use & LCs+ \\
CD3 & SP7 & Fuzhou Maixin Biology, Fuzhou, People's Republic of China & Ready to use & T lymphocyte+ \\
CD5 & SPI9 & Fuzhou Maixin Biology, Fuzhou, People's Republic of China & Ready to use & T lymphocyte+ \\
CD20 & L26 & Fuzhou Maixin Biology, Fuzhou, People's Republic of China & Ready to use & B lymphocyte+ \\
CD21 & EP3093 & Fuzhou Maixin Biology, Fuzhou, People's Republic of China & Ready to use & Follicular dendritic cells+ \\
CD68 & KPI & Fuzhou Maixin Biology, Fuzhou, People's Republic of China & Ready to use & Tissue cells+ \\
Ki-67 & MIB-I & Fuzhou Maixin Biology, Fuzhou, People's Republic of China & Ready to use & I0\% \\
P63 & MX013 & Fuzhou Maixin Biology, Fuzhou, People's Republic of China & Ready to use & + \\
Pax-5 & SP34 & Fuzhou Maixin Biology, Fuzhou, People's Republic of China & Ready to use & B lymphocyte+ \\
SI00 & 4C4.9 & Fuzhou Maixin Biology, Fuzhou, People's Republic of China & Ready to use & LCs+ \\
TdT & MX010 & Fuzhou Maixin Biology, Fuzhou, People's Republic of China & Ready to use & Immature T lymphocytes+
\end{tabular}

Abbreviations: eMNT, ectopic micronodular thymoma; LCs, Langerhans cells.
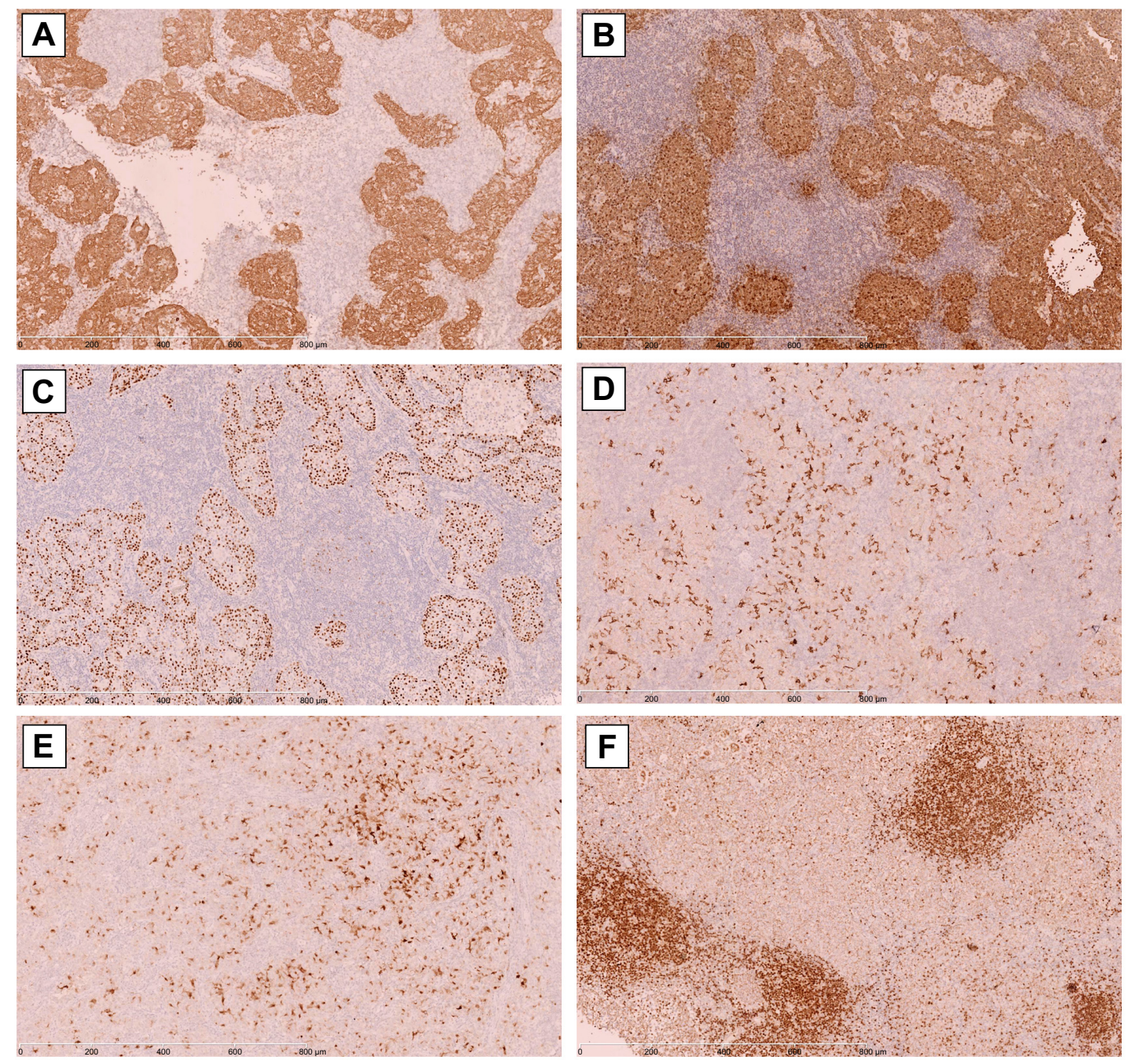

Figure 3 Immunohistochemical staining of the thymoma.

Notes: Proliferation of epithelial tumor cells were stained by CK (pan) (A), CK5/6 (B), and P63 (C). Proliferated LCs were positive for CDIa (D) and SI00 (E). Mature B lymphocytes were positive for Pax-5 (F). Scale bar is $800 \mu \mathrm{m}$. (Original magnification $\times 100$.)

Abbreviation: LCs, Langerhans cells. 
reactive for $\mathrm{CD} 3$ and $\mathrm{CD} 5$. A small number of phagocytes $\left(\mathrm{CD} 68^{+}\right)$, follicular dendritic cells (DCs, $\mathrm{CD} 21^{+}$), and immature $\mathrm{T}$ lymphocytes $\left(\mathrm{TdT}^{+} / \mathrm{CDla}^{+}\right)$were present in the stroma.

On the basis of the histological and immunohistochemical findings, the case was eventually diagnosed as a cervical eMNT. The patient underwent a local resection and remained well during the 4 months of follow-up.

\section{Discussion}

MNT, with suspected medullar origin, ${ }^{7}$ is a rare variant of thymic neoplasm with unclear pathogenesis. It was reported that MNTs might be related to immunodeficiency, including myasthenia gravis. ${ }^{8-11}$ Most cases are asymptomatic and are discovered incidentally during medical examination or a surgical procedure. Some patients are symptomatic and experience chest pain and shortness of breath., ${ }^{8,12,13}$

To date, only a few dozen cases of MNT have been described in the published literature (Table 2). - $-6,8,9,10,12-19^{-19}$ Only three cases of MNTs have been reported to have an ectopic site and all of them were located in the neck. ${ }^{4-6} \mathrm{In}$ the current case, the eMNT was also found in the neck. This frequently presenting position of MNT in the neck could be explained by the derivation of the thymus. The primordial thymus is derived from both endoderm and ectoderm of the ventral portion of the third pharyngeal pouch. During the sixth week of gestation, the epithelium of the pharyngeal pouch proliferates and forms these primordial thymus. The primordial thymus then migrates to the midline and descends to the final anatomic positions in the anterior mediastinum by the ninth week. ${ }^{20,21}$ The migration pathway forms the thymopharyngeal tract running from the angle of the mandible to the manubrium of the sternum. Normally, this tract degenerates completely during development. However, thymic vestiges (or ectopic thymic tissue) may occasionally persist in the neck, thyroid, or chest cavity along this pathway. ${ }^{20,21}$ Thus, cervical thymic anomalies including thymomas may occur as a consequence of thymic vestiges.

The most predominant characteristic of MNT is the prominent lymphoid stroma that mainly contains B lymphocytes, $\mathrm{T}$ lymphocytes, and plasma cells. In our case, there were numerous B and T lymphocytes present within the stroma; scattered plasma cells and eosinophilic granulocytes were also observed. The presence of the aforementioned cells is regarded as an immune response of the host to tumor antigens or unrelated antigens. ${ }^{2,8,10,14}$ This response, with an unclear initiating mechanism, was observed to be restricted to this subtype of thymoma. ${ }^{2}$ However, such an immune reaction suggests a beneficial process. ${ }^{2,3,8,10,14}$
The formation of lymphoid stroma with lympoid follicles is also closely related with LCs proliferation. Normally, LCs are located at the corticomedullary junction of the thymus, playing an important role in antigen presentation. After engulfing antigens, LCs migrate to the regional lymph nodes and then differentiate into DCs. DCs have a strong capability to stimulate $\mathrm{T}$ lymphocytes by presenting antigens. ${ }^{14}$ In MNTs, tumor cells abnormally overexpress various chemokines for recruiting $\mathrm{T}$ and $\mathrm{B}$ lymphocytes. ${ }^{10}$ Then the host antitumor immune response is initiated: LCs process tumor antigen capture and presentation, after which they migrate to the surrounding stroma containing immature T lymphocytes. LCs differentiate into DCs in the stroma. DCs activate $\mathrm{T}$ lymphocytes and induce antigen-specific B lymphocyte proliferation. Ultimately, the stromal lymphoid follicles are formed. ${ }^{14}$

In our case, we also noticed that the $\mathrm{S} 100^{+} / \mathrm{CD} 1 \mathrm{a}^{+} \mathrm{LCs}$ were primarily located within tumor nodules. It was reported that LCs might serve as supporting components and proliferate within the tumor nests, although they were recruited by chemotactic factors. ${ }^{14}$ Proliferation and infiltration of LCs might imply a favorable biological behavior of MNTs. The presence of stomal lymphoid hyperplasia and LC proliferation in MNTs often leads to a delayed progression and prolonged survival. ${ }^{14}$

Several differential diagnostic considerations should be mentioned. 1) Type $A$ and type $A B$ thymoma: The morphology of tumor cells in type $A / A B$ thymoma is similar to those in MNT. Tumor cells in type A thymoma are arranged in a large-sheet pattern rather than a nodular pattern and are often CD20 positive. Fibrous components instead of lymphocytes are seen in the stoma. Type AB thymoma contains focally epithelial nodules and lymphoid components. The nodules are lobulated and separated by fibrous components. Epithelial cells are not observed in the lymphoid components. Occasionally, MNT may be accompanied by type $\mathrm{A}$ and/or type $\mathrm{AB}$ thymoma, which should be identified carefully. 2) Thymic carcinoma: Tumor cells with enlarged nuclei proliferate in an infiltrating pattern. Signs of malignancy are obvious, such as cytological atypia and increased mitotic activity. 3) Lymph node metastasis of carcinoma: The patients often have a history of carcinoma. The tumor cells show malignant features such as atypia and a higher proliferation index. In our case, atypia and mitotic activity of tumor cells were occasionally observed by hematoxylin and eosin and immunohistochemical staining. 4) LC histiocytosis: Langerhans-type cells typically proliferate in a clustering pattern with reactive infiltration of eosinophile 


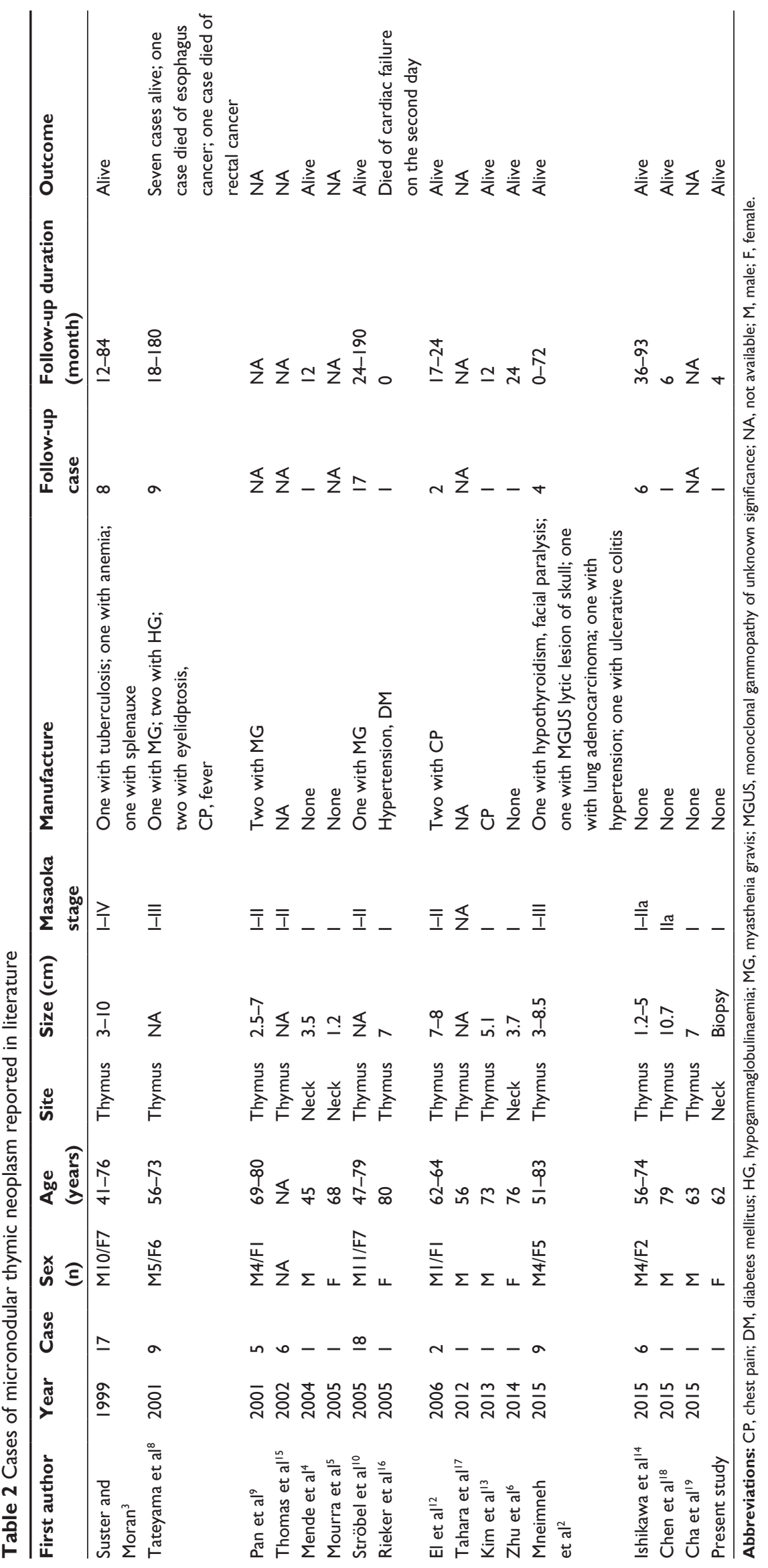


granulocytes. $^{22}$ In this case, eosinophile granulocytes and LCs $\left(\mathrm{CD} \mathrm{a}^{+} / \mathrm{S} 100^{+}\right)$were scattered in the tumor nodules, which implied that the MNT was associated with nonneoplastic proliferation of LCs. 5) Follicular DC sarcoma: This originates from follicular DCs. Cytological atypia, increased mitotic count, and intranuclear pseudoinclusions are helpful for differential diagnosis. 6) Sebaceous lymphadenoma: It is mainly composed of clearly defined squamous cell nests with focally sebaceous gland differentiation. Mitotic activities are rarely seen among the tumor cells. The vacuolated cytoplasm is often clear because of focal sebaceous differentiation, while the boundaries of the nuclei are often unclear.

The prognosis of MNT is closely related with Masaoka stage. More than $96 \%$ of reported MNTs belonged to Stages I and II; hence, the tumors were generally well encapsulated or only slightly invasive. Surgical resection is the mainstay of treatment. No recurrence or metastasis has ever been reported in a case of MNT. In the presented case, the patient was alive and free of related disease during the follow-up period of 4 months. Because of the limited number of reported cases, long-term outcomes of MNTs remain unclear. Further investigation is needed to improve our knowledge.

\section{Acknowledgment}

This study was supported by the Natural Science Foundation of Liaoning Province of China (no: L2015598).

\section{Disclosure}

The authors report no conflicts of interests in this work.

\section{References}

1. Levine GD, Rosai J. Thymic hyperplasia and neoplasia: a review of current concepts. Hum Pathol. 1978;9:495-515.

2. Mneimneh WS, Gökmen-Polar Y, Kesler KA, Loehrer PJ Sr, Badve S. Micronodular thymic neoplasms: case series and literature review with emphasis on the spectrum of differentiation. Mod Pathol. 2015;28: $1415-1427$.

3. Suster S, Moran CA. Micronodular thymoma with lymphoid B-cell hyperplasia: clinicopathologic and immunohistochemical study of eighteen cases of a distinctive morphologic variant of thymic epithelial neoplasm. Am J Surg Pathol. 1999;23:955-962.
4. Mende S, Moschopulos M, Marx A, et al. Ectopic micronodular thymoma with lymphoid stroma. Virchows Arch. 2004;444:397-399.

5. Mourra N, Duron F, Parc R, Flejou JF. Cervical ectopic thymoma: a diagnostic pitfall on frozen section. Histopathology. 2005;46:583-585.

6. Zhu P, Yan F, Ao Q, et al. Langerhans cells proliferation in ectopic micronodular thymoma with lymphoid stroma: a case report. Int J Clin Exp Pathol. 2014;7:7262-7267.

7. Travis WD, Brambilla E, Burke AP, et al. World Health Organization Classification of Tumours. Pathology and Genetics of Tumours Lung, Pleura, Thymoma and Heart. Lyon: LARC Press; 2015:187-243.

8. Tateyama H, Saito Y, Fujii Y, et al. The spectrum of micronodular thymic epithelial tumours with lymphoid B-cell hyperplasia. Histopathology. 2001;38:519-527.

9. Pan CC, Chen WY, Chiang H. Spindle cell and mixed spindle/ lymphocytic thymomas: an integrated clinicopathologic and immunohistochemical study of 81 cases. Am J Surg Pathol. 2001;25:111-120.

10. Ströbel P, Marino M, Feuchtenberger M, et al. Micronodular thymoma: an epithelial tumour with abnormal chemokine expression setting the stage for lymphoma development. J Pathol. 2005;207:72-82.

11. Oba T, Ono M, Lesato A, et al. Lipid-rich carcinoma of the breast that is strongly positive for estrogen receptor: a case report and literature review. OncoTargets Ther. 2016;9:1641-1646.

12. El MF, Braham E, Ayadi A, et al. Micronodular thymoma with lymphoid stroma: report of two cases and particular association with thymic lymphoid hyperplasia in one case. Pathology. 2006;38:586-588.

13. Kim NR, Lee JI, Ha SY. Micronodular thymoma with lymphoid stroma in a multilocular thymic cyst: a case study. Korean J Pathol. 2013;47: 392-394.

14. Ishikawa $\mathrm{Y}$, Tateyama $\mathrm{H}$, Yoshida $\mathrm{M}$, et al. Micronodular thymoma with lymphoid stroma: an immunohistochemical study of the distribution of Langerhans cells and mature dendritic cells in six patients. Histopathology. 2015;66:300-307.

15. Thomas De MV, Zemoura L, Dulmet E. [Thymoma with epithelial micronodules and lymphoid hyperplasia: six cases of a rare and equivocal subtype]. Ann Pathol. 2002;22:177-182. French.

16. Rieker RJ, Aulmann S, Schnabel PA, et al. Cystic thymoma. Pathol Oncol Res. 2005;11:57-60.

17. Tahara S, Takami K, Omiya H, et al. [Micronodular thymoma with lymphoid stroma (MNT)]. Kyobu Geka. 2012;65:1045-1048. Japanese.

18. Chen CW, Chuang SS, Pan ST. Micronodular thymoma with lymphoid stroma diagnosed with core needle biopsy: a case report. Anal Quant Cytopathol Histpathol. 2015;37:206-210.

19. Cha YJ, Han J, Kim J, Lee KS, Shim YM. A rare case of mixed type a thymoma and micronodular thymoma with lymphoid stroma. J Pathol Transl Med. 2015;49:75-77.

20. Courcoutsakis N, Patronas N, Filie A C, et al. Ectopic thymus presenting as a thyroid nodule in a patient with the Carney complex. Thyroid. 2009;19:293-296.

21. Tunkel DE, Erozan YS, Weir EG. Ectopic cervical thymic tissue: diagnosis by fine needle aspiration. Arch Pathol Lab Med. 2001;125: 278-281.

22. Harmon CM, Brown N. Langerhans cell histiocytosis: a clinicopathologic review and molecular pathogenetic update. Arch Pathol Lab Med. 2015;139:1211-1214.
OncoTargets and Therapy

\section{Publish your work in this journal}

OncoTargets and Therapy is an international, peer-reviewed, open access journal focusing on the pathological basis of all cancers, potential targets for therapy and treatment protocols employed to improve the management of cancer patients. The journal also focuses on the impact of management programs and new therapeutic agents and protocols on

Submit your manuscript here: http://www.dovepress.com/oncotargets-and-therapy-journal

\section{Dovepress}

patient perspectives such as quality of life, adherence and satisfaction. The manuscript management system is completely online and includes a very quick and fair peer-review system, which is all easy to use. Visit http://www.dovepress.com/testimonials.php to read real quotes from published authors. 